\title{
Open Circuit Stator Winding Fault Detection of Induction Machines from Transient Data Using Nature Inspired Optimization Algorithms
}

\author{
Salaheddine Ethni \\ School of Engineering \\ Newcastle University \\ Newcastle upon Tyne, UK \\ salaheddine.ethni@ncl.ac.uk
}

\author{
Andrew Smith \\ School of Engineering \\ Newcastle University \\ Newcastle upon Tyne, UK \\ andrew.smith@ncl.ac.uk
}

\author{
Hamza Khalfalla \\ School of Engineering \\ Newcastle University \\ Newcastle upon Tyne, UK \\ hamza.khalfalla@ncl.ac.uk
}

\author{
Muez Shiref \\ School of Engineering \\ Newcastle University \\ Newcastle upon Tyne, UK \\ muez.shiref@ncl.ac.uk
}

\begin{abstract}
This paper investigates the performance of two Nature Inspired Optimization Algorithms (NIOA): Bacterial Foraging Optimization (BFO) and Particle Swarm Optimization (PSO), which are used for early fault detection on Induction Machine (IM) stator windings, to prevent sudden, catastrophic, breakdowns. An open-circuit stator winding fault is experimentally studied. This scheme uses time domain measurements obtained during transients to validate the capability of this technique, and in conjunction with the NIOA, estimates the parameters of the IM mathematical model, detects stator winding faults, and gives information about its type and location. Only stator voltages, currents, and rotor speed are evaluated using experimental data obtained from a wound rotor three-phase IM. The validity and effectiveness of the proposed method using the transient data is verified, showing its accuracy, prediction capability, and sensitivity without the need of prior knowledge of various fault signatures.
\end{abstract}

Index Terms-- Induction machine, nature inspired optimization algorithms, condition monitoring.

\section{INTRODUCTION}

$\mathrm{I}^{\mathrm{n}}$ nduction machines play an essential role in industrial applications due to their well-known advantages of cost, reliability, and robustness. However, during their lifetime they are exposed to numerous stresses which can result in parameter changes and modes of failures. Consequently, to prevent downtime, losses caused by unscheduled maintenance, and lost revenues, condition monitoring is important to identify developing faults in their early stages, before severe motor faults occur [1, 2]. Faults can then be treated before severe motor damage occurs, thus decreasing repair costs and unplanned shutdown time. Therefore, robust and simple fault identification methods are essential to detect unexpected motor faults. Costly and complicated conventional techniques [3] usually involve the use of sensors fitted in the machine measuring and sensing temperature or vibration as well as professionally analysed data [1, 4].

For detecting winding and machine faults, the authors of [5, 6] analysed terminal current waveforms, using collected data under steady-state operating condition. Other methods may involve the calculation of quantities such as input power [7] or negative sequence components [8]. Recently, some researchers have used data acquired under start-up operating conditions to detect broken rotor bars [9] and to estimate machine parameters, with the use of steady-state models discussed in [10-16].

The most common IM winding faults are turn-to-turn, phase-to-phase, coil-to-coil and coil-to-ground [17], and stator related breakdowns of IM's account for a large percentage of reported faults [18, 19]. In squirrel cage rotor machines, cracked bars, and bad connections to the end rings can occur, while short circuits of the rotor laminations is a common fault in both squirrel cage and wound rotor machines [20]. Stator open-circuit faults are one of the more common and possibly critical in IM's. These faults start as small shorts between several turns in the same winding, producing high currents which cause severe localized heating that rapidly expands to a larger part of the winding, giving additional advanced degradation, and finally serious turn-toground faults. Insulation failures between the windings and ground can cause a large ground current to flow, which can permanently damage the core of the machine.

The stator itself is also subjected to various stresses during operation due to high temperatures, and movement of the laminations and coils. These factors usually lead to insulation failure, which eventually produce different types of stator faults. Conventional stator insulation failure protection in an industrial environment is by ground fault relays, and negative-sequence or phase current balance relays. However, with unbalanced line voltages, negative-sequence relays would cause nuisance trips. Ground fault relays would also not be effective for early fault detection purposes [18].

A proposed fault identification technique using external measurements voltages, currents, and rotor speed information has been proposed by the authors [11]. In this paper, an NIOA method is implemented to estimate the values of machine parameters which give the best possible match between the performance of the faulty experimental machine, and its mathematical model, thus identifying both the location and type of the winding fault. A schematic diagram of the fault identification technique can be seen in Figure 1.

Stator currents are calculated from an induction machine dynamic model and compared to the actual measured currents, producing a set of current errors which are integrated and then summed to give an overall error function. 


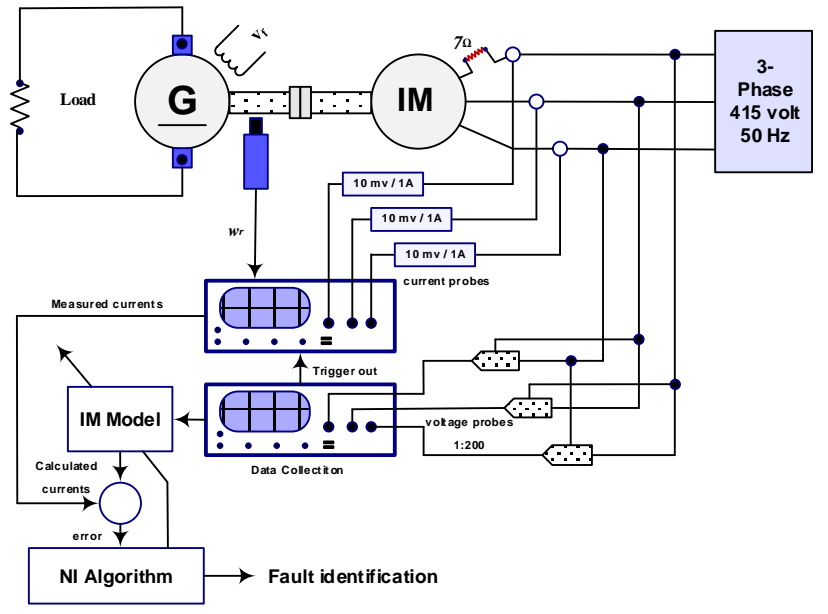

Fig. 1 Block diagram of the proposed fault identification technique / Experimental set up

When the machine is in its healthy state, there is a high correlation between its effective parameters and the model parameters resulting in a small calculation error.

If a fault develops in the machine, its electrical parameters are modified, and when the measured currents are compared with those calculated, there will be a large calculation error giving a fast indication that a fault is present. Fault identification is carried out by continuously adjusting the machines model parameters off-line, using NIOA, to achieve the minimum error between the measured and calculated stator currents, and the new set of model parameters defines the type and location of the fault. In this paper, two NIOA optimization techniques will be used and compared: Particle Swarm Optimization (PSO) and Bacterial Foraging Optimization (BFO). Unlike many other methods, it should be noted that this technique does not require any expert prior knowledge of the type of fault or its location; both are identified as an integral part of the optimisation process.

Experimental testing of the proposed scheme is based on a wound rotor, three phase induction machine, and has been carried out to justify the proposed fault identification algorithm, with open-circuit stator winding fault considered. The results obtained confirm the effectiveness and capability of the two proposed nature inspired optimization algorithms (PSO and BFO) to detect and locate the fault, searching sixdimensional solution space using data gathered as the speed changed between two different values.

\section{InDUCTION MACHINE MATHEMATICAL MODEL}

A three-phase $\mathrm{ABC} / \mathrm{abc}$ model of an induction machine was developed using Matlab/Simulink software, and combined with INOA to identify open-circuit stator winding faults. This $\mathrm{ABC} / \mathrm{abc}$ model, obtained from the standard machine voltage equations, is shown in (1):
$\left[\begin{array}{c}V_{s A} \\ V_{s B} \\ V_{s C} \\ V_{r a} \\ V_{r b} \\ V_{r c}\end{array}\right]=\left[\begin{array}{cccccc}R_{s A}+p L_{s s} & p M_{s s} & p M_{s s} & p M_{s r} \cos \theta_{r} & p M_{s r} \cos \theta_{r 1} & p M_{s r} \cos \theta_{r 2} \\ p M_{s s} & R_{s B}+p L_{s s} & p M_{s s} & p M_{s r} \cos \theta_{r 2} & p M_{s r} \cos \theta_{r} & p M_{s r} \cos \theta_{r 1} \\ p M_{s s} & p M_{s s} & R_{s C}+p L_{s s} & p M_{s r} \cos \theta_{r 1} & p M_{s r} \cos \theta_{r 2} & p M_{s r} \cos \theta_{r} \\ p M_{s r} \cos \theta_{r} & p M_{s r} \cos \theta_{r 2} & p M_{s r} \cos \theta_{r 1} & R_{r a}+p L_{r r} & p M_{r r} & p M_{r r} \\ p M_{s r} \cos \theta_{r 1} & p M_{s r} \cos \theta_{r} & p M_{s r} \cos \theta_{r 2} & p M_{r r} & R_{r b}+p L_{r r} & p M_{r r} \\ p M_{s r} \cos \theta_{r 2} & p M_{s r} \cos \theta_{r 1} & p M_{s r} \cos \theta_{r} & p M_{r r} & p M_{r r} & R_{r c}+p L_{r r}\end{array}\right] \cdot\left[\begin{array}{c}I_{S A} \\ I_{s B} \\ I_{s C} \\ I_{r a} \\ I_{r b} \\ I_{r c}\end{array}\right]$

Here, $\left(V_{s A}, V_{s B}, V_{s C}\right)$ and $\left(I_{s A}, I_{s B}, I_{s C}\right)$ are the stator winding voltages and currents respectively, $\left(V_{r a}, V_{r b}, V_{r c}\right)$ and $\left(I_{r a}, I_{r b}, I_{r c}\right)$, the rotor winding voltages and currents, $\left(R_{s A}, R_{s B}, R_{s C}\right)$ and $\left(R_{r a}, R_{r b}, R_{r c}\right)$, the stator and rotor winding resistances, $L_{s s}$ and $L_{r r}$, the stator and rotor winding selfinductances, $M_{s s}$ and $M_{r r}$, the mutual inductance between pairs of stator and rotor windings, $M_{s r}$ is the peak value of the rotor position dependent mutual inductance between the stator and rotor winding pairs, $\theta_{r}$ is the rotor position angle, $\theta_{r 1}=\theta_{r}+2 \pi / 3$ and $\theta_{r 2}=\theta_{r}+4 \pi / 3$, and $p$ is the differential operator.

\section{PARTICLE SWARM OPTIMIZATION}

Particle Swarm Optimisation (PSO) is an iterative optimisation technique inspired by the biological behaviour of a swarm of birds or bees [21-23].

Unlike evolutionary optimization techniques, such as Genetic Algorithms, it is not based on the idea of the survival of the fittest. Instead, it is a collective method, in which members of the population cooperate to find a global optimum in a partially random way, and without any selection. Members of the population with the lower fitness functions are not discarded, they do survive, and can potentially be future successful members of the swarm. This technique has been explained in more details by the authors in previous papers $[11,12]$.

\section{BACTERIAL FORAGING OPTIMIZATION}

Bacterial Foraging Optimization (BFO) was introduced in 2002 by Passino [24]. The BFO is a stochastic search and optimization technique, based around the foraging behaviour of Escherichia coli (E. coli) bacteria, which takes advantage of a variety of bacterial swarming and social foraging behaviours. Unlike PSO where a collective method is used to find a global optimum without any selection, bacterial foraging is based on the idea of the survival of the fittest. The BFO algorithm has been applied previously by the authors using the same technique for IM stator and rotor winding fault identification in [14].

\section{EXPERIMENTAL RESULTS}

All the results obtained are experimentally verified using a $1.5 \mathrm{~kW}, 50 \mathrm{~Hz}, 240 \mathrm{~V}, 2$-pole wound rotor induction machine with star connected stator windings, and a short circuited delta connected rotor winding, coupled to a $3 \mathrm{~kW}$ DC machine, which is used as a generator to provide load torque necessary to emulate the transient operating conditions. 
Standard tests (dc, no-load and locked rotor tests) [25] were carried out to determine the machines nominal parameters (Table 1).

TABLE 1

INDUCTION MACHINE PARAMETERS

\begin{tabular}{|c|c|}
\hline PARAMETERS & Values \\
\hline Stator resistances & $R_{s}=5.88 \Omega$ \\
\hline Rotor resistances & $R_{r}=6.83 \Omega$ \\
\hline Stator self-inductances & $L_{s s}=0.729 \mathrm{H}$ \\
\hline $\begin{array}{c}\text { Rotor self-inductances } \\
\text { Mutual inductances between the stator } \\
\text { windings }\end{array}$ & $L_{r r}=0.578 \mathrm{H}$ \\
\hline $\begin{array}{c}\text { Mutual inductances between the rotor } \\
\text { windings }\end{array}$ & $M_{r r}=0.7 \mathrm{H}$ \\
\hline $\begin{array}{c}\text { Mutual inductance between stator and } \\
\text { rotor winding pairs }\end{array}$ & $M_{s r}=0.769 \mathrm{H}$ \\
\hline
\end{tabular}

To emulate the open-circuit stator winding fault condition, differential voltage probes, current probes, and a digital tachometer were used to measure the terminal voltages (Fig. 2), stator currents (Fig. 3) and rotor speed. Data was collected over a period of $0.8 \mathrm{sec}$, with a sampling interval of $1 \mathrm{~ms}$. For this test, data was gathered for a transient load application of $40 \%$ rated.

The acquired data was then processed off-line using the PSO and $\mathrm{BFO}$ algorithms to determine the effective parameters of the machine. The position of each particle/bacterium within the solution space $\mathrm{X}_{i}=\left(R_{s A}, R_{s B}, R_{s C}, R_{r a}, R_{r b}, R_{r c}\right)$ is a potential solution which can be applied to the machine model to evaluate a set of stator currents. Each parameter value must lie within a pre-defined search space and the overall calculation error; the Integral Absolute Error (IAE), as defined in (2). This error function is the objective function to be minimized by the algorithms.

$$
I A E=\sum_{k=1}^{n}\left(\left|I_{s A m}-I_{s A c}\right|+\left|I_{s B m}-I_{s B C}\right|+\left|I_{s C m}-I_{s C c}\right|\right) \Delta T
$$

where $\left(I_{s A m}, I_{s B m}, I_{s C m}\right)$ are the measured currents, $\left(I_{s A c}, I_{s B c}, I_{s C c}\right)$ are the calculated currents, $n$ is the number of samples and $\Delta T$ is the sampling period.

An open-circuit stator winding fault was created by connecting a $7 \mathrm{Ohm}$ resistance in series with stator phase ' $A$ ' winding, imitating an open-circuit fault in one phase, as shown in Fig. 1.

Normally, stator winding open-circuit faults remain undetected for extended periods of time, resulting a serious damage and high repairing costs. For the method implemented, the number of parameters to be optimized was restricted to six, to allow the algorithm to converge within the stop criteria (number of accepted steps) described earlier [1114], and the available computational resources. A large number of tests were conducted, and it was concluded that stator and rotor resistance values gave the best opportunity for convergence. Good results were obtained using the six winding resistances: $\mathrm{X}_{i}=\left(R_{s A}, R_{s B}, R_{s C}, R_{r a}, R_{r b}, R_{r c}\right)$ with the other parameters kept constant at their nominal values. The search space for the machine parameters was set as follows: $1 \leq R_{s} \leq 25$ and $1 \leq R_{r} \leq 25$.

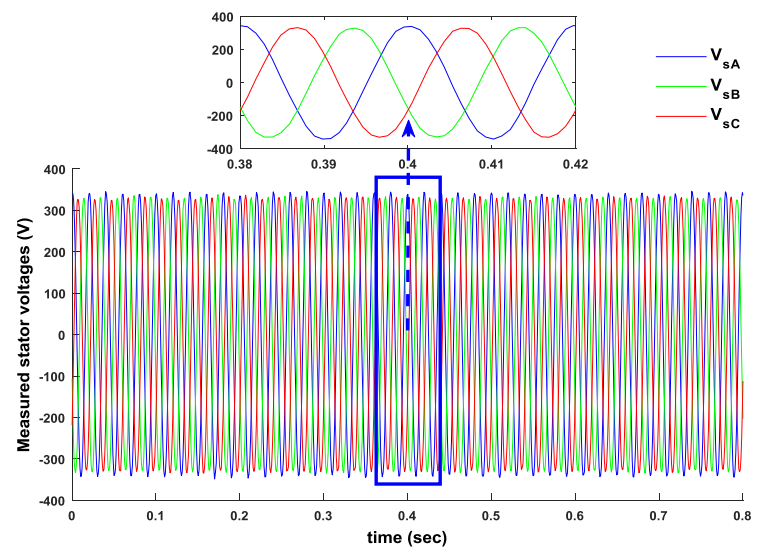

Fig. 2 Measured stator voltage waveforms; developing stator open-circuit winding fault, transient operating condition

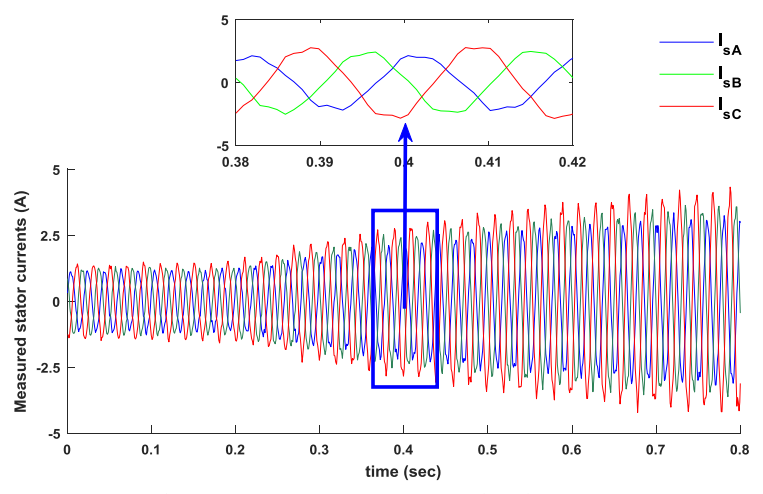

Fig. 3 Measured stator current waveforms; developing stator open-circuit winding fault, transient operating conditions

\section{A. Stator Open-circuit Winding Fault Identification Using PSO}

The PSO algorithm was implemented to identify the presence of a developing stator winding open-circuit fault, based on the experimental measurements. In this test, values of $c_{1}=0.5$ and $c_{\max }=1$ were used, together with a total swarm population of 8 particles ( 8 particles with six dimensions for each particles). Figures 4 and 5 show the estimated stator and rotor resistances, respectively. The error function corresponding to the existing best solution is shown in Fig. 10, and will be discussed in Section C. In this test the final estimated values of the stator and rotor resistances are given in Table 2. 


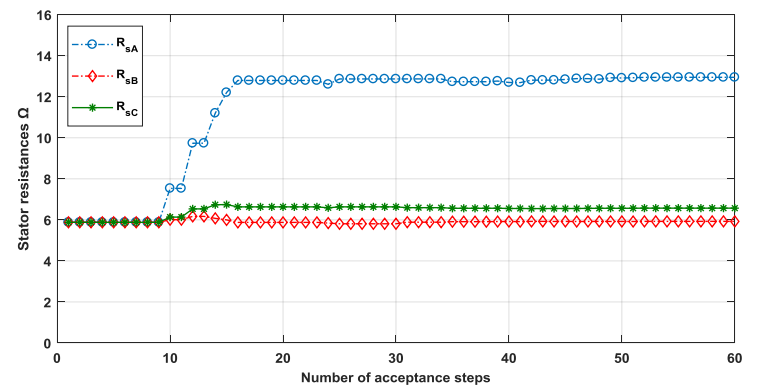

Fig.4 Estimated stator resistances obtained by PSO with open-circuit stator winding fault

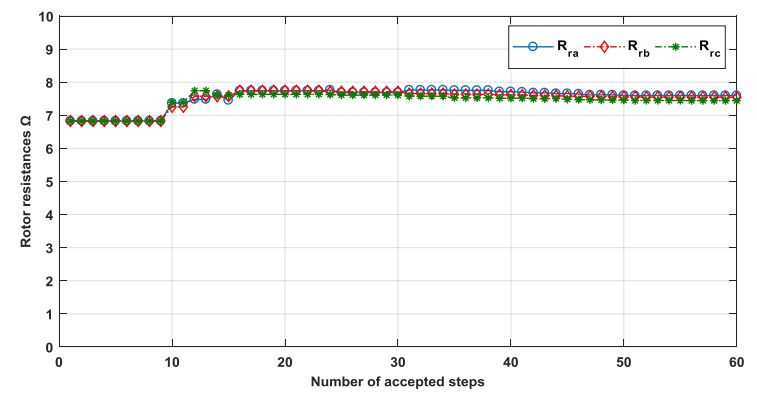

Fig. 5 Estimated rotor resistances obtained by PSO with open-circuit stator winding fault

As shown in Fig. 4, the PSO algorithm successfully identifies the presence of the stator open-circuit winding fault as indicated by the high value of $R_{s A}$ compared with $R_{s B}$ and $R_{s C}$, and the values of $R_{r a}, R_{r b}$, and $R_{r c}$ (Fig. 5) are comparable with their nominal value of $6.83 \Omega$.

Figure. 6 shows the measured transient stator current waveforms $\left(i_{s A m}, i_{s B m}, i_{s C m}\right)$ and the currents $\left(i_{s A c}, i_{s B c}, i_{s C c}\right)$ calculated using the final parameter values obtained by the PSO algorithm, showing good agreement between the two current waveforms. The number of iterations required to obtain convergence of the data sets (stator resistance and rotor resistance) was 480, and the calculation error falls from a maximum value of 1.1370 Amps per step (A.s) to 0.9381 A.s. The obtained rotor parameters are approximately the same, and are close to their nominal values, confirming the healthy state of the rotor.

\section{B. Stator Open-circuit Winding Fault Identification Using BFO}

A process similar to that used with PSO was implemented with the BFO for open-circuit stator winding fault identification. From trial runs, it was identified that the stator resistances were the most appropriate parameters combination to be used.

The BFO parameters necessary for implementation include the number of bacteria within the population $(S=8)$, the initial position of each bacterium within the solution space, the number of chemotactic steps $\left(N_{c}=10\right)$ taken during each bacterium lifetime, the maximum number of successive steps in any one swim sequence $N_{s}=4$ steps, the number of

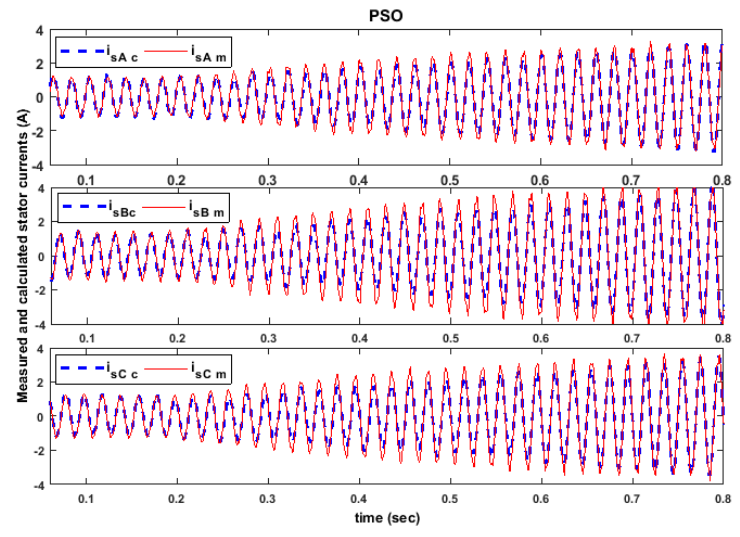

Fig. 6 Measured and calculated stator current waveforms using the estimated parameters obtained by PSO with open-circuit stator fault

reproduction $N_{r e}=4$, and the elimination / dispersal events $N_{e d}=2$ that occur during the BFO implementation. Figures. 7 and 8 show the BFO estimated stator and rotor resistances, respectively. The error function corresponding to the existing best solution is shown in Fig. 10, and the stator and rotor resistances estimated through the optimization process are given in Table 2. Excluding the computational time, the BFO algorithm successfully identifies the presence of the stator open-circuit winding fault as indicated by the high value of $R_{s A}$ compared with $R_{s B}$ and $R_{s C}$.



Fig. 7 Estimated stator resistances obtained by BFO with open-circuit stator winding fault



Fig. 8 Estimated rotor resistances obtained by BFO with open-circuit stator winding fault

Figure 9 shows the measured stator currents $\left(i_{s A m}, i_{S B m}, i_{S C m}\right)$ and the calculated stator currents $\left(i_{s A c}, i_{s B c}, i_{S C c}\right)$ using the final parameter values obtained by the BFO algorithm showing good agreement between the two current waveforms. 
The number of evaluations required to obtain convergence of the data sets (stator and rotor resistances) was 1586. The calculation error falls from a maximum value of 1.1066 A.s to 0.9289 A.s. The rotor parameters obtained are approximately at the same value, close to their nominal values, which confirming the healthy state of the rotor.

BFO



Fig. 9 Measured and calculated stator current waveforms using the estimated parameters obtained by BFO with open-circuit stator winding fault

\section{Comparison between PSO and BFO algorithms}

The bacterial foraging optimization algorithm requires a relatively long computational time for convergence because of its chemotactic feature. Compared to PSO, the BFO algorithm is more focused on local searches, so even when it does search globally, it does so less frequently through the elimination and dispersal procedures. The PSO algorithm overcomes this disadvantage by its co-operative multi-agent swarming nature and is clearly the most successful in this type of application.

Table 3 shows a comparison of the PSO results with those obtained using the BFO algorithm. The PSO algorithm had a success rate of approximately $80 \%$ when used with the transient measured current data, compared with a success rate of approximately $70 \%$ for the BFO algorithm. PSO was also substantially faster than BFO which requires a much larger number of investigations to produce consistent values for the estimated stator resistances (the number of investigations when conducting a BFO search being noticeably larger than the number of accepted solutions). However, even with the lower percentage of trails of BFO, elimination and dispersal increase the probability of obtaining better solutions as well as preventing the whole swarm to be stuck in a local minimum, which explaining the lower values of error that BFO obtained. Nevertheless, this study demonstrates the robust nature of the PSO process and its suitability to this type of nonlinear multivariable optimization problem as Fig. 10 shows. Here, PSO requires just 72 evaluations to give an indication of the fault compared to between 160 and 640 for the BFO, which depends upon of the number of swim sequences and error conditions. Both algorithms showed estimated stator and rotor parameters to converge to similar values, confirming that there is fault in the machine's stator windings.
TABLE 2.

FINAL VALUES OF STATOR AND ROTOR WINDING PARAMETERS OBTAINED USING PSO \& BFO WITH STATOR OPEN-CIRCUIT FAULT USING TRANSIENT DATA

\begin{tabular}{|c|c|c|}
\hline Algorithms & $\begin{array}{c}\text { Estimated } \\
\text { Parameters }\end{array}$ & Values \\
\hline \multirow{6}{*}{$\begin{array}{l}0 \\
\tilde{\Omega}\end{array}$} & \multirow{3}{*}{$\begin{array}{c}\text { Stator } \\
\text { resistances }\end{array}$} & $R_{s A}=12.9 \Omega$ \\
\hline & & $R_{s B}=5.9 \Omega$ \\
\hline & & $R_{s C}=6.6 \Omega$ \\
\hline & \multirow{3}{*}{$\begin{array}{c}\text { Rotor } \\
\text { resistances }\end{array}$} & $R_{r a}=7.5 \Omega$ \\
\hline & & $R_{r b}=7.6 \Omega$ \\
\hline & & $R_{r c}=7.5 \Omega$ \\
\hline \multirow{6}{*}{$\begin{array}{l}0 \\
\text { OT } \\
\infty\end{array}$} & \multirow{3}{*}{$\begin{array}{c}\text { Stator } \\
\text { resistances }\end{array}$} & $R_{s A}=13.7 \Omega$ \\
\hline & & $R_{s B}=6.3 \Omega$ \\
\hline & & $R_{s C}=6.3 \Omega$ \\
\hline & \multirow{3}{*}{$\begin{array}{c}\text { Rotor } \\
\text { resistances }\end{array}$} & $R_{r a}=6.7 \Omega$ \\
\hline & & $R_{r b}=6.7 \Omega$ \\
\hline & & $R_{r c}=7 \Omega$ \\
\hline
\end{tabular}

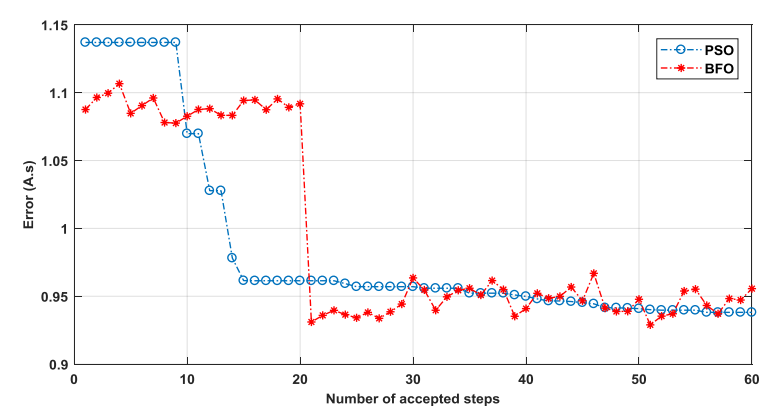

Fig. 10 Current error using the estimated parameters obtained by PSO with stator open-circuit winding fault

\section{CONCLUSION}

The use of two NIOA algorithms (PSO and BFO) to detect a developing induction machine open-circuit stator winding fault has been presented in this paper. The condition monitoring method is based on the comparison of measured machine stator currents with those obtained from a machine mathematical model, and then using the algorithms to minimise the resulting error function. The two algorithms have been shown to be effective in determining the winding fault type and location. However results show that the PSO algorithm is better suited for this type of application, achieving a success rate of about $80 \%$ compared with $70 \%$ for BFO algorithm with noticeably improved execution times because of the smaller number of function evaluations needed for convergence. 
TABLE 3

ALGORITHM COMPARISIONS; STATOR OPEN-CIRCUIT WINDING FAULTS

\begin{tabular}{|c|c|c|c|c|}
\hline \multicolumn{5}{|c|}{ Stator open-circuit fault } \\
\hline Algorithm & $\begin{array}{c}\text { Computational } \\
\text { time (sec) }\end{array}$ & $\begin{array}{c}\text { Current } \\
\text { error } \\
\text { (A) }\end{array}$ & $\begin{array}{c}\text { Number of } \\
\text { evaluations }\end{array}$ & $\begin{array}{c}\text { Success } \\
\text { Rate \% }\end{array}$ \\
\hline PSO & 384 & 0.940848 & 480 & $\begin{array}{c}80(120 \\
\text { trials })\end{array}$ \\
\hline BFO & 1269 & 0.955601 & 1586 & $\begin{array}{c}70(120 \\
\text { trials })\end{array}$ \\
\hline
\end{tabular}

\section{REFERENCES}

P. Zhang, Y. Du, T. G. Habetler, and B. Lu, "A Survey of Condition Monitoring and Protection Methods for MediumVoltage Induction Motors," IEEE Transactions on Industry Applications, vol. 47, no. 1, pp. 34-46, 2011.

[2] J. Jung et al., "Monitoring Journal-Bearing Faults: Making Use of Motor Current Signature Analysis for Induction Motors," IEEE Industry Applications Magazine, vol. 23, no. 4, pp. 12-21, 2017.

[3] P. J. Tavner, L. Ran, J. Penman, and H. Sedding, Condition monitoring of rotating electrical machines. London: Institution of Engineering and Technology, 2008.

[4] M. V. K. Chari, G. Bedrosian, J. A. Fealey, T. J. Sober, and J. Scheibel, "Incipient failure prediction of rotating electrical machinery by eddy current on-line monitoring method," IEEE Transactions on Magnetics, vol. 24, no. 6, pp. 2889-2891, 1988.

[5] M. E. H. Benbouzid, "A review of induction motors signature analysis as a medium for faults detection," IEEE Transactions on Industrial Electronics, vol. 47, no. 5, pp. 984-993, 2000.

[6] J. H. Jung, J. J. Lee, and B. H. Kwon, "Online Diagnosis of Induction Motors Using MCSA," IEEE Transactions on Industrial Electronics, vol. 53, no. 6, pp. 1842-1852, 2006.

[7] A. M. Trzynadlowski and E. Ritchie, "Comparative investigation of diagnostic media for induction motors: a case of rotor cage faults," IEEE Transactions on Industrial Electronics, vol. 47, no. 5, pp. 1092-1099, 2000.

[8] Q. Wu and S. Nandi, "Fast Single-Turn Sensitive Stator Interturn Fault Detection of Induction Machines Based on Positive- and Negative-Sequence Third Harmonic Components of Line Currents," IEEE Transactions on Industry Applications, vol. 46, no. 3, pp. 974-983, 2010.

[9] R. J. Romero-Troncoso, D. Morinigo-Sotelo, O. Duque-Perez, R. A. Osornio-Rios, M. A. Ibarra-Manzano, and A. Garcia-Perez, "Broken rotor bar detection in VSD-fed induction motors a startup by high-resolution spectral analysis," in 2014 International Conference on Electrical Machines (ICEM), 2014, pp. 1848-1854.

[10] M. S. N. Said, M. E. H. Benbouzid, and A. Benchaib, "Detection of broken bars in induction motors using an extended Kalman filter for rotor resistance sensorless estimation," IEEE Transactions on Energy Conversion, vol. 15, no. 1, pp. 66-70, 2000 .

[11] S. A. Ethny, P. P. Acarnley, B. Zahawi, and D. Giaouris, "Induction Machine Fault Identification using Particle Swarm Algorithms," in 2006 International Conference on Power Electronic, Drives and Energy Systems, 2006, pp. 1-4.

[12] S. A. Ethni, B. Zahawi, D. Giaouris, and P. P. Acarnley, "Comparison of particle swarm and simulated annealing algorithms for induction motor fault identification," in 2009 th IEEE International Conference on Industrial Informatics, 2009, pp. $470-474$

[13] S. A. Ethni, S. M. Gadoue, and B. Zahawi, "Inter-turn short circuit stator fault identification for induction machines using computational intelligence algorithms," in 2015 IEEE International Conference on Industrial Technology (ICIT), 2015, pp. 757-762.

[14] S. A. Ethni, S. M. Gadoue, and B. Zahawi, "Induction machine winding faults identification using Bacterial Foraging Optimization technique," in 7th IET International Conference on
Power Electronics, Machines and Drives (PEMD 2014), 2014, pp. 1-6.

[15] A. M. Alturas, S. M. Gadoue, B. Zahawi, and M. A. Elgendy, "On the Identifiability of Steady-State Induction Machine Models Using External Measurements," IEEE Transactions on Energy Conversion, vol. 31, no. 1, pp. 251-259, 2016.

[16] A. M. Alturas, S. Gadoue, M. A. Elgendy, B. Zahawi, and A. S. Abdel-Khalik, "Structural Identifiability Analysis of Steady-State Induction Machine Models," in 2015 4th International Conference on Electric Power and Energy Conversion Systems (EPECS), 2015, pp. 1-6

[17] A. H. Bonnett and G. C. Soukup, "Cause and analysis of stator and rotor failures in three-phase squirrel-cage induction motors," IEEE Transactions on Industry Applications, vol. 28, no. 4, pp. 921-937, 1992.

[18] R. M. Tallam et al., "A Survey of Methods for Detection of Stator-Related Faults in Induction Machines," IEEE Transactions on Industry Applications, vol. 43, no. 4, pp. 920-933, 2007.

[19] R. M. Tallam et al., "A survey of methods for detection of stator related faults in induction machines," in 4th IEEE International Symposium on Diagnostics for Electric Machines, Power Electronics and Drives, 2003. SDEMPED 2003., 2003, pp. 35-46.

[20] G. K. Singh and S. a. Ahmed Saleh Al Kazzaz, "Induction machine drive condition monitoring and diagnostic research-a survey," Electric Power Systems Research, vol. 64, no. 2, pp. 145 158, 2003/02/01/ 2003.

[21] M. Clerc, Particle swarm optimization. John Wiley \& Sons, 2010

[22] S. He, Q. H. Wu, and J. R. Saunders, "Group Search Optimizer: An Optimization Algorithm Inspired by Animal Searching Behavior," IEEE Transactions on Evolutionary Computation, vol. 13, no. 5, pp. 973-990, 2009.

[23] S. Binitha and S. S. Sathya, "A survey of bio inspired optimization algorithms," International Journal of Soft Computing and Engineering, vol. 2, no. 2, pp. 137-151, 2012.

[24] K. M. Passino, "Biomimicry of bacterial foraging for distributed optimization and control," IEEE Control Systems, vol. 22, no. 3, pp. 52-67, 2002.

[25] "IEEE Standard Test Procedure for Polyphase Induction Motors and Generators," IEEE Std 112-2017 (Revision of IEEE Std 112 2004), pp. 1-115, 2018 